\title{
A EDUCAÇÃO DAS PESSOAS COM O TRANSTORNO DO ESPECTRO AUTISTA: AVANÇOS E DESAFIOS
}

\author{
EDUCACIÓN POPULAR CON EL TRASTORNO DEL ESPECTRO AUTISTICO: \\ AVANCES Y DESAFÍOS
}

\section{EDUCATION OF PEOPLE WITH THE AUTISTIC SPECTRUM DISORDER: ADVANCES AND CHALLENGES}

\author{
André Luiz Alvarenga de SOUZA ${ }^{1}$ \\ Alexandra Ayach ANACHE ${ }^{2}$
}

RESUMO: Este trabalho aborda os avanços que depreenderam dos diplomas legais que asseguram os direitos das pessoas com Transtorno do Espectro Autista (TEA). Para esse fim, o objetivo deste trabalho é analisar as mudanças ocorridas nos últimos dez anos, que culminou com a aprovação da Lei 12.764/12 (Lei Berenice Piana). A metodologia é de natureza qualitativa, do tipo documental, pois se trata de uma revisão sistemática da literatura do campo da Educação e dos Direitos Humanos. Os aspectos centrais deste estudo voltaram-se para as garantias dos direitos das pessoas com TEA no âmbito da educação e saúde. Durante a realização desse estudo foi observado na literatura, que há abordagens distintas usadas para ajudar na inclusão dos indivíduos com (TEA), todavia com sansão da Lei 12.764/12, esses indivíduos obtiveram uma grande vitória, porém ainda há muito que se fazer.

PALAVRAS-CHAVE: Inclusão. Transtorno do espectro autista. Direitos humanos. Inclusão. Educação.

RESUMEN: Este documento aborda los avances que han surgido de los diplomas legales que garantizan los derechos de las personas con trastorno del espectro autista (TEA). Con ese fin, el objetivo de este trabajo es analizar los cambios que han ocurrido en los últimos diez años, que culminaron con la aprobación de la Ley 12.764 / 12 (Lei Berenice Piana). La metodología es de naturaleza cualitativa, de tipo documental, ya que es una revisión sistemática de la literatura en el campo de la Educación y los Derechos Humanos. Los aspectos centrales de este estudio se centraron en garantizar los derechos de las personas con TEA en el campo de la educación y la salud. Durante la realización de este estudio, se observó en la literatura que existen diferentes enfoques utilizados para ayudar a la inclusión de personas con TEA, sin embargo, con la sanción de la Ley 12.764 / 12, estas personas obtuvieron una gran victoria, pero aún queda mucho por hacer.

PALABRAS CLAVE: Inclusión. Trastorno del espectro autista. Derechos humanos. Inclusión. Educación.

${ }^{1}$ Universidade Federal de Mato Grosso do Sul (UFMS), Campo Grande - MS - Brasil. Doutorando no Programa de Pós-Graduação em Educação. ORCID: https://orcid.org/0000-0002-2685-6611.E-mail: andrealvarengams@gmail.com

${ }^{2}$ Universidade Federal de Mato Grosso do Sul (UFMS), Campo Grande - MS - Brasil. Professora no Programa de Pós-Graduação em Educação. Pós-Doutorado em Educação (UNB). ORCID: https://orcid.org/0000-00027937-4448. E-mail: alexandra.anache@gmail.com

RPGE- Revista on line de Política e Gestão Educacional, Araraquara, v. 24, n. esp. 2, p. 1035-1053, set. 2020. e-ISSN: 1519-9029 
ABSTRACT: This paper addresses the advances that have emerged from the legal documents that ensure the rights of people with Autistic Spectrum Disorder (ASD). To that end, the aim of this paper is to analyze the changes that have occurred in the last ten years, which culminated in the approval of Law 12.764/12 (Berenice Piana Law). The methodology is of a qualitative nature, of documentary type, as it is a systematic review of the literature in the field of Education and Human Rights. The central aspects of this study focused on guaranteeing the rights of people with ASD in the field of education and health. During the performance of this study, it was observed in the literature that there are different approaches used to help the inclusion of individuals with ASD, however with the approval of Law 12,764/12, these individuals achieved a great victory, but there is still much to be done.

KEYWORDS: Inclusion. Autistic spectrum disorder. Human rights. Inclusion. Education.

\section{Introdução}

Este trabalho aborda os avanços e os desafios que depreenderam dos diplomas legais que asseguraram os direitos das pessoas com Transtorno do Espectro Autista (TEA). Para esse fim, o objetivo deste trabalho foi analisar as mudanças ocorridas nos últimos dez anos, que culminou com a aprovação da Lei 12.764/12 (Lei Berenice Piana) (BRASIL, 2012).

O Transtorno do Espectro Autista (TEA) impacta a comunicação, a interação social, a imaginação e o comportamento do indivíduo, os quais podem causar prejuízos no desenvolvimento social e intelectual destas pessoas. Este transtorno pode variar em grau leve, moderado e severo, o que requer avaliações minuciosas para identificar as suas necessidades e possibilidades de aprendizagem.

Considerando as mudanças conceituais sobre o entendimento das características de indivíduos com TEA, os quais demonstraram que há uma amplitude de comportamentos e necessidades específicas, questionamos se os diplomas legais produzidos em âmbito nacional asseguram os direitos aos bens e serviços disponibilizados na sociedade para este público. Tendo em vista esse pressuposto, a problemática deste estudo centrou-se no seguinte questionamento: Quais as principais alterações nas legislações referentes aos direitos das pessoas com (TEA)? Para responder a esse questionamento, o objetivo geral deste estudo é conhecer quais as alterações nas legislações referentes aos direitos das pessoas com deficiência e com (TEA).

A metodologia empregada neste estudo foi de natureza qualitativa, de caráter exploratório documental e de revisão bibliográfica, sobre a Educação de pessoas com Transtorno do Espectro Autista (TEA) e sobre os Direitos Humanos. Segundo Minayo (2010) este tipo de pesquisa procura “desvelar" processos sociais que ainda são pouco conhecidos e 
que pertencem a grupos particulares, proporcionando a construção ou a revisão de novas abordagens, conceitos e categorias referentes ao fenômeno estudado.

A pesquisa documental, enquanto método de investigação, busca a realidade social que não traz uma única concepção filosófica de pesquisa, pode ser utilizada tanto nas abordagens de natureza positivista como também naquelas de caráter compreensivo, com enfoque mais crítico (SILVA et al., 2009). Segundo Bravo (1991), são documentos todas as realizações produzidas pelo homem que se mostram como indícios de sua ação e que podem revelar suas ideias, opiniões e formas de atuar e viver. Nesta concepção é possível apontar vários tipos de documentos: os escritos; os numéricos ou estatísticos; os de reprodução de som e imagem; e os documentos-objeto, dentre outros, que é o caso dessa pesquisa que se debruçou sobre as Leis e Decretos vigentes no país para a construção do estudo.

A pesquisa do tipo exploratório contribui para sistematizar o conjunto produções, subsidiando as explicações sobre o assunto em estudo (SEVERINO, 2007, p. 13). De acordo com Denzin e Lincoln (2006) o pesquisador dedica-se ao estudo de situações do passado, que possam ser associadas às situações presentes, em relação a uma ou algumas das unidades sociais: indivíduo(s), grupo(s), instituição(ões), comunidade(s) para o desenrolar de uma pesquisa ou estudo.

Centramos a pesquisa em artigos científicos publicados e de acesso livre, disponíveis na base de dados da Coordenação de Aperfeiçoamento de Pessoal de Nível Superior - CAPES, produzidos no período de 2010-2020. Este período foi marcado pela promulgação de um conjunto de diplomas legais de âmbito internacional e nacional, dentre os quais estão a Constituição Federativa do Brasil de 1988, Lei Brasileira 7.853/89 que trata sobre os Portadores de Deficiência, Lei de Acessibilidade, No. 10.098/2000, Declaração de Salamanca (1994), Convenção sobre os Direitos da Pessoa com deficiência de 2006 (ONU), ratificada no Brasil em 2008, Decreto 6.949 de 25 de agosto de 2009, Promulga a Convenção Internacional sobre os Direitos das Pessoas com Deficiência e seu Protocolo Facultativo, assinados em Nova York, em 30 de março de 2007. Lei no 13.146, de Institui a Lei Brasileira de Inclusão da Pessoa com Deficiência (Estatuto da Pessoa com Deficiência) 6 de julho de 2015 e Lei 12.764/12 (Lei Berenice Piana) (BRASIL, 1988; 1989; 2000; 2009; 2015; 2012).

Selecionamos os artigos científicos recuperados com os descritores, a saber: direitos das pessoas com Transtorno do Espectro Autista e Educação das Pessoas com Transtorno do Espectro Autista, disponíveis na base de dados no período de janeiro a junho de 2020.

A pesquisa das produções acadêmicas foi realizada em consonância ao que alvitra a revisão integrativa da literatura, a qual visa sistematizar os conhecimentos científicos 
produzidos sobre o tema em tela. Sobre isso, Botelho, Cunha e Macedo (2011, p. 133) nos ensina que este método pode ser

[...] incorporado às pesquisas realizadas em outras áreas do saber, além das áreas da saúde e da educação, pelo fato de ele viabilizar a capacidade de sistematização do conhecimento científico e de forma que o pesquisador aproxime-se da problemática que deseja apreciar, traçando um panorama sobre sua produção científica para conhecer a evolução do tema ao longo do tempo e, com isso, visualizar possíveis oportunidades de pesquisa.

Pretende-se, nos limites deste espaço, apresentar o conjunto das produções acadêmicas que estudaram os direitos à educação das pessoas com Transtorno do Espectro Autista (TEA), considerando os dispositivos legais assegurados nas legislações vigentes.

\section{Aspectos conceituais sobre o Transtorno do Espectro Autista}

O discurso de inclusão e de igualdade predominante do mundo globalizado primaram pelo reconhecimento entre os sujeitos e pelo respeito às diferenças. Isso significa afirmar que os seus valores culturais precisam ser reconhecidos em suas especificidades, por serem fatores determinantes da constituição das relações sociais, portanto é necessário compreender que o conceito de pessoas com deficiência é construído de acordo com estes valores. O Transtorno do Espectro Autista, também é classificado como deficiência em 2012 e ratificado em 2015 com o Estatuto da Pessoa com Deficiência. Registre-se que ele é um conceito que vem sendo modificado ao longo do tempo, considerando os avanços científicos sobre as especificidades que compõe este espectro. Segundo Schimidt (2012),

O conceito de autismo tal como conhecemos hoje decorre principalmente das publicações iniciais de Kanner (1943), seguidas por Kolvin (1971) e Rutter (1972), que o diferenciaram das psicoses infantis, sendo definitivamente consolidado como um transtorno do desenvolvimento através dos manuais internacionais de classificação DSM-III (APA, 1986) e CID-10 (WHO, 1992). Ainda hoje o conceito permanece em contínua revisão, sendo propostas novas e importantes mudanças para sua caracterização no DSM-V.

No Manual Diagnóstico e Estatístico de Transtornos Mentais (DSMV - Diagnostic and Statistical Manual, que significa Manual de Diagnóstico e Estatística), que foi criado pela Associação Americana de Psiquiatria voltada para o diagnóstico de transtornos mentais, lançado em 22 de maio de 2013, o TEA engloba as variações desse Transtorno, que nas edições anteriores eram denominados de: autismo infantil precoce, autismo infantil, autismo de Kanner, autismo de alto funcionamento, autismo atípico, transtorno global do desenvolvimento sem 
outra especificação, transtorno desintegrativo da infância e Transtorno de Asperger. Os diagnósticos consideram o nível de gravidade em relação à interação e comunicação. Eles são classificados de acordo com o nível de gravidade, a saber: 1. exigindo apoio; 2. exigindo apoio substancial e 3: exigindo apoio muito substancial (DSMV, 2013). Desse modo, a pessoa diagnosticada com estas características precisa de investimentos educacionais e de saúde para que consiga obter êxitos em suas atividades acadêmicas, laborais e entre outras da vida cotidiana. Este direito está assegurado no art. $3^{\circ}$, inciso IV, artigo 205 e artigo 206, inciso I da Constituição Federal de 1988.

Em que pese às mudanças conceituais sobre o TEA, as quais expressam maior entendimento sobre as suas características, cada família tem sua crença sobre este transtorno o que pode gerar sentimentos, atitudes, impactando a aceitação e superação das adversidades impostas pela condição da pessoa afetada. Por exemplo, alguns membros da família entendem que autismo é sinônimo de isolamento social, e, por conseguinte, evitam manter relações com eles - situação essa, que poderá se agravar ainda mais, aprofundando as suas dificuldades de interação social. A esse respeito, importa destacar que é crucial que a pessoa com (TEA) consiga desenvolver habilidades sociais, que possam ajudá-lo a ter uma interação com o meio social mais adequada. Silva, Araújo e Almeida, (2016) argumentam que às vezes, alterações simples e muito pequenas podem fazer grande diferença na mudança comportamental de indivíduos com (TEA).

Andrade (2017) afirma que há várias formas de manifestação do autismo, podendo variar em grau, justificando com isso o uso da palavra espectro. Além disso, cada pessoa com características semelhantes de TEA apresentam atributos diferentes, os quais se expressam em seus comportamentos. Esta conclusão foi referendada em nossas experiências em avaliações de gêmeos univitelinos. Portanto, torna-se desafiador para os profissionais construírem propostas de trabalhos que promovam a educação destes indivíduos, considerando as suas especificidades (SANTOS; VIEIRA, 2017). Portanto, é fundamental reconhecer que os (as) estudantes com TEA possuem limites e possibilidades, as quais devem ser consideradas e exploradas, respectivamente (STRIEDER; ZIMMERMANN, 2010). O princípio da Educação Inclusiva defende que é necessário construir condições para que todos indistintamente possam desfrutar dos bens e serviços da sociedade, sem qualquer tipo de discriminação, conforme assegurou a Constituição brasileira de 1988, visando superar a concepção de deficiência fundamentada no capacitismo, ou seja, é um termo empregado entre as pessoas com deficiência, quando se coloca em dúvidas as suas capacidades para executarem determinadas atividades. 
De acordo com Telles, (2010) tem-se que o cenário da política pública relacionada à pessoa com deficiência muda totalmente a partir do marco da Convenção sobre os Direitos da Pessoa com Deficiência, de 2006, da Organização das Nações Unidas (ONU), ratificada pelo Brasil em 2008, passando do modelo de integração para a sociedade inclusiva, o qual o movimento político das pessoas com deficiência, trabalhou muito para alcançar um novo patamar de dignidade humana, não obstante que ainda convive com resquícios de segregação. Nos estudos de (DIGIROLAMO, 2010, p. 42), destaca-se a Convenção da ONU, sobre os Direitos das Pessoas com Deficiência, ratificada pelo governo brasileiro em 2008, que reitera a necessidade de que os Estados tomem medidas para assegurar o acesso de pessoas com deficiência a serviços de saúde e educação, este evento representa um importante avanço, de sua elaboração até sua concretização, sendo que as pessoas com deficiência foram protagonistas na construção dessa política pública para que fossem reconhecidas em sua autonomia, direito a fazer sua própria escolha, vida independente e a não discriminação mediante o lema "Nada sobre nós sem nós" (JUNIOR, 2010).

\section{Aspectos legais e jurídicos das pessoas com (TEA)}

A partir da Constituição de 1988, o Brasil elaborou um conjunto de diplomas legais para garantir que os direitos das pessoas com deficiência fossem assegurados. Desse modo, elegemos como marcos de conquistas a esse respeito. Elencamos as principais Leis que abordam a temática em referência.

Trazemos primeiramente a Lei Federal no 12.764/2012, de 27 de dezembro de 2012, que institui a Política Nacional de Proteção dos Direitos da Pessoa com Transtorno do Espectro Autista; e altera o $\S 30$ do art. 98 da Lei no 8.112, de 11 de dezembro de 1990. Sendo que a referida Lei resultou de projeto (PLS 168/2011) de autoria da Comissão de Direitos Humanos e Legislação Participativa (CDH), presidida pelo senador Paulo Paim (PT-RS). O Projeto de Lei Suplementar (PLS), que estabelece os direitos fundamentais da pessoa autista e a equipara à pessoa com deficiência para todos os efeitos legais, cria um cadastro único com a finalidade de produzir estatísticas nacionais sobre o assunto. Ainda que a Lei estabeleça a criação de um cadastro único para a pessoa com (TEA) em 2012, somente 8 anos depois em 2020, é que por iniciativa dos movimentos sociais de pais e mães de autistas e dos próprios autistas adultos que a Presidência da República do Brasil, 
Congresso Nacional no dia 11 de dezembro de 2019. A proposta foi apresentada pela deputada federal Rejane Dias (PT-PI) e alterou dispositivos da Lei 12.764, de 2012, que instituiu a Política Nacional de Proteção dos Direitos da Pessoa com Transtorno do Espectro Autista, sendo que a mesma garante prioridade nas áreas de saúde, educação e assistência social (AGÊNCIA BRASIL, 2020).

Os avanços foram significativos do ponto de vista social e que diante aos progressos estabelecidos, ainda necessitam de enquadramentos conforme destaca a Agência Brasil,

A carteira será expedida pelos órgãos responsáveis pela execução da política de proteção dos direitos da pessoa com transtorno do espectro autista dos estados, do Distrito Federal e dos municípios, mediante requerimento, acompanhado e relatório médico, com indicação do código da Classificação Estatística Internacional de Doenças e Problemas Relacionados à Saúde (CID) (AGÊNCIA BRASIL, 2020).

No ano de 2019 a Presidência da República do Brasil, publica a Lei nº 13.861/2019, sancionada que trata da inclusão de informações específicas sobre pessoas com autismo, nos censos demográficos realizados a partir do ano 2019 pelo Instituto Brasileiro de Geografia e Estatística (IBGE) (AGÊNCIA BRASIL, 2020).

Sendo desta forma um fator preponderante para o acompanhamento e mapeamento no Brasil das pessoas com o Transtorno do Espectro Autista, pois Municípios, Estados e a União não possuem registros oficiais sobre a quantificação de pessoas com esse transtorno, e a partir deste censo, será possível quantificar e propor políticas públicas mais efetivas para essa parcela da população.

O Decreto Federal $n^{\circ} 8.368 / 2014$, de 02 de dezembro de 2014, que regulamentou a Lei n 12.764 é uma Ementa Constitucional que assegura os direitos e obrigações previstos na Convenção Internacional sobre os Direitos da Pessoa com Deficiência e seu Protocolo Facultativo, promulgados pelo Decreto $\mathrm{n}^{\circ}$ 6.949, de 25 de agosto de 2009, incluindo os indivíduos com o diagnóstico de TEA (CAMARA DOS DEPUTADOS, 2014). Assim, esse grupo poderia ter os mesmos direitos à educação e a outros bens e serviços na sociedade assegurados pela citada Lei. Em tempo, Silva (2017, p. 24), afirma que conquista de Direitos foi acaudilhada por Berenice Piana, mãe de um menino autista, que decidiu denunciar a situação dos autistas brasileiros e iniciar a luta para a elaboração de leis e políticas públicas que abarcasse os indivíduos com TEA, os quais sempre foram delegados à suas próprias sortes.

Berenice Piana representa o coletivo de pessoas que vivenciaram as dificuldades do diagnóstico para obterem atendimentos especializados e educação escolarizada adequada. (CAVACO apud SILVA; ARAÚJO; ALMEIDA, 2016) comenta que muitos pais queixam-se 
de que não tem tempo de ler ou entender teorias sobre o TEA, e, por isso a importância da Lei 12.764/12 (Lei Berenice Piana-LBP), que, através de uma linguagem acessível explicita as legislações pertinentes aos indivíduos com (TEA). A partir de sua promulgação da LBP, os indivíduos com (TEA) começaram a usufruir dos mesmos direitos das outras pessoas com deficiência, que neste diapasão trazemos a baila a Lei $n^{0}$ 13.146, de 6 de julho de 2015, que dispõe sobre a Lei Brasileira de Inclusão da Pessoa com Deficiência, mais conhecida como Estatuto da Pessoa com Deficiência, para dar os devidos amparos e suportes legais, que legitimam a Lei Federal $n^{\circ} 12.764 / 2012$. Gabrilly (2015) pontua que em consonância a este cenário, o Estatuto da Pessoa com Deficiência (EPCD), trouxe novidades para a ordem legislativa brasileira, tendo expresso no texto da LBI, in verbis:

Art. 1o É instituída a Lei Brasileira de Inclusão da Pessoa com Deficiência (Estatuto da Pessoa com Deficiência), destinada a assegurar e a promover, em condições de igualdade, o exercício dos direitos e das liberdades fundamentais por pessoa com deficiência, visando à sua inclusão social e cidadania. Parágrafo único. Esta Lei tem como base a Convenção sobre os Direitos das Pessoas com Deficiência e seu Protocolo Facultativo, ratificados pelo Congresso Nacional por meio do Decreto Legislativo no 186, de 9 de julho de 2008, em conformidade com o procedimento previsto no $\S 30$ do art. 50 da Constituição da República Federativa do Brasil, em vigor para o Brasil, no plano jurídico externo, desde 31 de agosto de 2008, e promulgados pelo Decreto no 6.949 , de 25 de agosto de 2009 , data de início de sua vigência no plano interno.

Embora o Brasil tenha ratificado os mais importantes tratados internacionais de direitos humanos e dos avanços na elaboração e promulgação dos diplomas legais brasileiros, a realidade é de desigualdade e exclusão (SILVA, 2017, p. 43). Em tal perspectiva, (TIBYRIÇA, 2015) comenta que é função do Estado desenvolver os mecanismos necessários para assegurar a harmonia social e as mesmas condições de existência para todos os membros da sociedade. E, também, é sua função corrigir eventuais desvios quando os primados fundamentais não forem respeitados. Dessa forma, esse conjunto de deveres do Estado compreende a defesa dos direitos fundamentais. No tocante às pessoas com deficiência é dever do Estado brasileiro protegê-las das desigualdades para que todos tenham direito a uma vida digna.

As pessoas com deficiência se mantiveram fora do contexto social por muitos anos, por serem considerados como incapazes de adaptar-se a esse contexto, e no decorrer da história necessitaram lutar pelos seus interesses chamando atenção para suas limitações, com isso foi possível dar início a grande mudança no processo de inclusão social.

De acordo com o último censo brasileiro de 2010, considera-se que há em torno de 25 milhões de brasileiros com algum tipo de deficiência, ou seja, aproximadamente $15 \%$ da 
população. Quanto à terminologia adequada, não são mais usados termos como excepcionais, deficiente, pessoa portadora de deficiência ou portadora de necessidades especiais, por essa razão, esse estudo explicita que a terminologia apropriada é pessoa com deficiência (COEPEDE, 2011).

Nessa linha de raciocínio, refletir sobre a questão dos direitos das pessoas com deficiência, em especial do indivíduo com (TEA) significa hoje discutir cidadania e democracia, igualdade social e respeito às diferenças.

Pensar a mesma questão no contexto brasileiro nos obriga a uma série de análises que envolvem justiça social e direitos humanos e nos levam a considerar as incontáveis imposições econômicas e sociais que fazem dessa parcela da população um radical exemplo de exclusão social em nosso país (IBDD, 2008). No ano 2000, foi criada a Lei n. ${ }^{\circ}$ 10.098/2000 (Lei da Acessibilidade), que dá o entendimento de que acessibilidade é a, possibilidade e condição de alcance para utilização, com segurança e autonomia, dos espaços, mobiliários e equipamentos urbanos, das edificações, dos transportes e dos sistemas e meios de comunicação, por pessoa com deficiência ou com mobilidade reduzida, sendo um avanço para todas as pessoas com deficiência (BRASIL, 2000).

Diante o exposto, depreende-se que uma das missões do Estado Democrático de Direito é proteger e salvaguardar os direitos tidos como fundamentais dos brasileiros. Assim, a tarefa principal do Estado é assegurar e fornecer os meios e elementos para assegurar as aptidões, as aspirações e anseios dos indivíduos.

E os fundamentos do Estado Democrático de Direito Brasileiro são calcados na soberania, na cidadania, na dignidade da pessoa humana, nas liberdades, na igualdade, nos valores sociais do trabalho, da livre-iniciativa e do pluralismo (GONÇALVES, 2015). Dentro desse contexto, pontua-se que abordar as leis de inclusão e todos os seus dispositivos legais no Brasil para o indivíduo com (TEA) e para qualquer outro cidadão com deficiência, é falar de democracia e de direitos humanos.

\section{Avanços e desafios sobre a educação de pessoas com TEA a partir dos diplomas legais}

Os avanços estabelecidos na sociedade brasileira até o momento no campo da educação, direitos humanos e da pessoa com deficiência e da pessoa com (TEA), foram muitos, mas ter esses avanços e não os ver serem praticados é um descabimento sem tamanho. Diante o exposto dentro da pesquisa, foram encontrados 14 artigos na base de dados da CAPES, com os descritores supramencionados, sendo que 12 deles abordaram temas relacionados à Educação 
de Pessoas com TEA e 2 trabalhos foram capturados com o descritor Direito à Educação de pessoas com TEA. Eles foram analisados e caracterizados, considerando o referencial teórico metodológico e respectivas contribuições atinentes à inclusão da pessoa com o TEA mediante o disposto nos Diplomas Legais apresentados neste estudo.

A fontes das revistas cientificas, que compuseram este estudo são de origem nacional e internacional, sendo que uma delas se enquadra no conceito A2 e demais receberam os conceitos B1, B2, B3 e B4. Foram encontrados 1 artigo publicado em 2012 e 2 em 2013, 2 em 2015, 1 em 2017, 1 em 2018 e 3 em 2019. Identifica-se tímido aumento das produções acadêmicas nos últimos 5 anos.

A metodologia empregadas nos trabalhos foram: estudos exploratórios da literatura, e os demais trabalhos, usaram estudos de casos, grupos focais, entrevistas, construção de escalas, análise documental e análise de rede social. Esta é uma tendência metodológica empregada no campo da Educação Especial. Os participantes dos estudos foram crianças, adolescentes, familiares e professores. Observou-se a carência de pesquisa sobre adultos que apresentam autismo.

Os referenciais teóricos empregados para a análises dos resultados foram: 3 na histórico cultural (2), psicanálise (2), análise do comportamento (1), socioecológica (1), cognitiva (1), psicometria (1), análise de redes sociais (1). Estas informações, em sua maioria, não estavam disponíveis nos resumos, conforme o exigido nas normas técnicas de apresentação de artigos científicos.

Os assuntos dos artigos foram resultados de pesquisas que se destinaram analisar: as condições educacionais de estudantes com autismo (MORI, 2016), a competência social de criança em contexto educacional (CAMARGO; BOSA, 2012), a percepção de criança no ensino regular (CANEDA; CHAVES, 2015), os desafios da prática docente no acompanhamento de uma criança com autismo, (LUZ; GOMES; LIRA, 2017) as tendências das produções acadêmicas de pessoas com TEA no campo da Psicologia e da Educação (GUEDES; TADA, 2015), a opinião pública sobre o autismo (ORTEGA et al., 2013), análise do conteúdo de redes sociais (ROSSI, et al., 2018), proposta de escala para avaliação qualidade de vida de indivíduos com autismo (CUESTA GÓMEZ; GRAU; FERNÁNDEZ, 2013), proposta de protocolo de avaliação de criança com autismo (MARQUES; BOSA, 2015) análise das relações entre a pesquisa científica sobre autismo e a sociedade, como foco na Expertise e Experiência (RIOS, 2019), pesquisa sobre a psicoterapia e sua relação entre a crianças e seus pais (RAMIRES et al., 2019) e estudo documental dos registro dos critérios para indicação de atendimentos especializados para os indivíduos com autismo (ARAÚJO; VERAS; VARELLA, 2019). Diante 
do exposto, identificamos a predominância de estudos circunscritos aos estudos de casos em ambientes educacionais, a redes de serviços, aos diagnósticos e atendimentos de saúde. A concepção de autismo referenciado em dez textos se aproxima do conceito mencionado no artigo $1^{\circ}$, parágrafo $1^{\circ}$, lei $n^{\circ} 12.764$, de 27 de dezembro de 2012, que são consideradas pessoas com transtorno do espectro autista aquela que apresenta síndrome clínica caracterizada da seguinte forma:

I - deficiência persistente e clinicamente significativa da comunicação e da interação sociais, manifestada por deficiência marcada de comunicação verbal e não verbal usada para interação social; ausência de reciprocidade social; falência em desenvolver e manter relações apropriadas ao seu nível de desenvolvimento;

II - padrões restritivos e repetitivos de comportamentos, interesses e atividades, manifestados por comportamentos motores ou verbais estereotipados ou por comportamentos sensoriais incomuns; excessiva aderência a rotinas e padrões de comportamento ritualizados; interesses restritos e fixos.

Note-se que há esforços dos(as) autores(as) em considerar os indivíduos com TEA como sendo pessoas com deficiências, requerendo os direitos de obterem atendimentos adequados nas redes de serviços de saúde e de educação. Não obstante, identificou-se um trabalho que estudou a opinião pública sobre o autismo e constatou a associação desta condição de desenvolvimento atípico com doença. (SILVA DA LUZ; GOMES; LIRA, 2017). Pessotti (1984) informou que Esquirol fez a distinção entre "loucura e idiotia" (termos empregados na época).

Simões (2019) ensina que a;

até então, estas eram vistas como situações diferentes de um mesmo estado. Esquirol é o principal incentivador da consolidação de uma negativação da idiotia. Para o autor, idiotia não é uma doença e, sim, um estado notadamente marcado por ausências e carências das manifestações das faculdades intelectuais e seu desenvolvimento. Para ele, tais carências e ausências acabam por impossibilitar os processos educativos. Muitos outros importantes intelectuais seguiram, reformularam e aprimoraram as indicações teóricas fatalistas de Esquirol.

Considerando a complexidade dos dois conceitos, arrisca-se afirmar que a doença é uma alteração que pode ser ordem física e mental que compromete o equilíbrio do indivíduo, e dependendo da sua extensão pode ocasionar limitações para as pessoas acometidas. Ela pode ser crônica, controlável e passageira. A deficiência implica em entender a condição social em que ela se insere, conforme ensina Diniz (2003, p. 1): 
Deve-se entender deficiência como um conceito amplo e relacional. É deficiência toda e qualquer forma de desvantagem resultante da relação do corpo com lesões e a sociedade. Lesão, por sua vez, engloba doenças crônicas, desvios ou traumas que, na relação com o meio ambiente, implica em restrições de habilidades consideradas comuns às pessoas com mesma idade $\mathrm{e}$ sexo em cada sociedade. Lembro que deficiência é um conceito aplicado a situações de saúde e doença e, em alguma medida, é relativo às sociedades onde as pessoas deficientes vivem.

No que se refere à saúde, os trabalhos demonstraram esforços para atenderem os indivíduos com TEA, construindo protocolos e escalas. No entanto, o trabalho de Araújo, Veras e Varella (2019) demonstra a necessidade de cuidados para a adoção de critérios para a indicação das abordagens terapêuticas para estas pessoas. Não obstante, eles conseguiram identificar que há avanços na política brasileira para que se atenda às necessidades específicas deste público, conforme estes autores asseveraram:

O progresso da política de saúde brasileira é um fato concreto, que se consolida por medidas gradativamente implantadas para proporcionar um bem-estar e uma assistência integral e humanizada às pessoas com TEA. Esse fato torna-se mais importante quando se observa a preocupação por políticas que atendam às demandas das pessoas com TEA, de modo específico. Os esforços do Ministério da Saúde em organizar uma rede de atenção e oferecer serviços de reabilitação especializados são de grande relevância e se mostram coerentes com os princípios do SUS. Assim, é importante destacar e reconhecer esses avanços e esforços; mas também, reconhecer a necessidade de definir melhor os papéis das instituições envolvidas na atenção especializada e os serviços de reabilitação (baseados em evidências) que serão ofertados por profissionais qualificados para sua prática (ARAÚJO; VERAS; VARELLA, 2019, p. 96).

Os artigos que fizeram referências à educação de crianças com autismo, e, defenderam a necessidade de ampliação de estudos sobre os processos de aprendizagem, com ênfase na construção de estratégias metodológicas adequadas para que o processo de escolarização se efetive. Eles aludiram sobre as condições precárias do sistema educacional brasileiro para que este direito se efetive.

Mori (2016) se valendo das dificuldades informadas pela comunidade escolar sobre o tipo de inclusão que os(as) estudantes com TEA experimentam nas escolas brasileiras, apresenta o debate sobre a viabilidade de se incluir todas as crianças com esta característica. Ela argumentou a favor da inclusão total e defende a necessidade de transformação da escola em um espaço para o encontro entre as diferenças. Com ênfase no poder transformador da aprendizagem escolarizada, afirma que se precisa investir em pesquisas sobre as especificidades desta condição, conforme a sua afirmação: 
Ainda sabemos pouco sobre como lidar com os alunos com transtorno na escola. Sob o prisma do desenvolvimento mediante o ensino, podemos avançar para além da educação como direito e estabelecer bases mais transformadoras para os estudos e as práticas pedagógicas com esse alunado. (MORI, 2016, p. 58).

Guedes e Tada, (2015) corroboram sobre a necessidade de maiores investimentos em todas as áreas e indicam que houve avanços sobre a compreensão das características sobre o TEA, no entanto, mediante a algumas divergências teóricas, ressaltam a necessidade de estudos sobre os fatores etiológicos, os quais refletem nas diferentes formas de se atender e educar estas pessoas. E para isso, os investimentos devem se direcionar para produção de conhecimentos sobre os limites e as possibilidades de destas pessoas para que a inclusão social ocorra de forma a garantir qualidade de vida melhor a eles. As autoras alertam que a divergência de ideias sobre este transtorno não é um fator limitador, mas, contraditoriamente pode representar um campo propício para construção de soluções para o atendimento e acompanhamento deste grupo de pessoas.

Diante do exposto, o conjunto a literatura disponível sobre o tema em referência ainda é escasso, requerendo pesquisas sobre o impacto dos avanços das políticas públicas que viabilize os bens e serviços para as pessoas com autismo, mas, para isso, é fundamental que outros estudos sobre as caraterísticas e processos educativos ganhem centralidade.

\section{Considerações finais}

A aprovação da Lei 12.764/12, denominada Berenice Piana, expressou o esforço de familiares e pessoas que apresentam características autistas tivessem os mesmos direitos aos bens e serviços especiais assegurados na Lei Brasileira de Inclusão (2015) (BRASIL, 2012). Soma-se a esse fato, as mudanças conceituais sobre as características deste grupo que vinham se encaminhando em âmbito internacional e nacional, as quais reconheceram a heterogeneidade dos comportamentos autistas (espectro), e, portanto, os métodos de identificações no âmbito da saúde devem ser aprimorados, assim como no âmbito escolar, os planejamentos educacionais deveriam atender as necessidades específicas de cada estudante, pautando os processos avaliativos.

Em que pese o que está previsto na legislação em vigor, que assegurou o direito à educação para todos, o laudo médico ainda é condicionante para que o(a) estudante possa ter acompanhamentos especial. Soma-se a isso, a importância que os membros da escola dão para os conhecimentos sobre a deficiência e suas características, quando que para ensinar qualquer 
pessoa, precisa-se conhecer os seus processos de aprendizagens, suas motivações, de suas relações com conhecimento e com a vida escolar.

O princípio da educação inclusiva se constrói diariamente por meio das ações e relações pedagógicas, exigindo mudanças substanciais na organização e gestão do trabalho didático. Neste sentido, o conjunto das produções acadêmicas identificadas neste estudo, sinalizaram para a necessidade de investimentos em pesquisas que se dediquem ao campo da educação destas pessoas, vez que os seres humanos se constituem e se transformam no movimento que as suas condições de vida.

Ressalta-se a importância das conquistas declaradas em cada artigo e dos diplomas legais vigentes, no entanto, precisamos avançar para que o respeito às diferenças seja o pilar das relações sociais.

\section{REFERÊNCIAS}

AGÊNCIA BRASIL. Bolsonaro sanciona lei que institui carteira nacional do autista.

Disponível em: https://agenciabrasil.ebc.com.br/politica/noticia/2020-01/bolsonaro-sancionalei-que-institui-carteira-nacional-do-autista. Acesso em: 10 jun. 2020.

ANDRADE, J. M. Teoria e prática da educação especial. Manaus; UEA Edições, 2017.

ARAÚJO, J. A. M. R.; VERAS, A. B.; VARELLA, A. A. B. Breves considerações sobre a atenção à pessoa com transtorno do espectro autista na rede pública de saúde. Rev. Psicol. Saúde, Campo Grande, v. 11, n. 1, jan./abr. 2019.

ARAÚJO, L. A.; COSTA FILHO, W. M. O estatuto da pessoa com deficiência - EPCD (Lei 13.146, de 06.07.2015): algumas novidades. Revista dos Tribunais, v. 962, p. 65-80, 2015.

BASIL. Lei n. 12.764, de 27 de dezembro de 2012. Institui a Política Nacional de Proteção dos Direitos da Pessoa com Transtorno do Espectro Autista; e altera o $§ 30$ do art. 98 da Lei no 8.112, de 11 de dezembro de 1990. Brasília, DF, 28 dez. 2012. Disponível em: https://www2.camara.leg.br/legin/fed/lei/2012/lei-12764-27-dezembro-2012-774838publicacaooriginal-138466-pl.html. Acesso em: 12 jun. 2020.

BOTELHO, L. L. R.; CUNHA, C. C. A.; MACEDO, M. O método da revisão integrativa nos estudos organizacionais. Gestão e Sociedade, Belo Horizonte, v. 5, n. 11, p. 121-136, maio/ago. 2011.

BRASIL. Constituição da República Federativa do Brasil. Brasília: Senado Federal, 1988.

BRASIL. Decreto n. 8.368, de 02 de dezembro de 2014. Regulamenta a Lei no 12.764, de 27 de dezembro de 2012, que institui a Política Nacional de Proteção dos Direitos da Pessoa com Transtorno do Espectro Autista. Brasília, DF, 3 dez. 2014. Disponível em: https://www2.camara.leg.br/legin/fed/decret/2014/decreto-8368-2-dezembro-2014-779648publicacaooriginal-145511-pe.html.Acesso em: 12 dez. 2020. 
BRASIL. Decreto n. 8.368, de 2 de dezembro de 2014. Regulamenta a Lei no 12.764, de 27 de dezembro de 2012, que institui a Política Nacional de Proteção dos Direitos da Pessoa com Transtorno do Espectro Autista. Brasília, 3 dez. 2014. Disponível em:

https://www2.camara.leg.br/legin/fed/decret/2014/decreto-8368-2-dezembro-2014-779648publicacaooriginal-145511-pe.html. Acesso em: 08 jun. 2020.

BRASIL. Lei n. 10.098, de 19 de dezembro de 2000. Estabelece normas gerais e critérios básicos para a promoção da acessibilidade das pessoas portadoras de deficiência ou com mobilidade reduzida, e dá outras providências. Brasília, 20 dez. 2000. Disponível em: https://www2.camara.leg.br/legin/fed/lei/2000/lei-10098-19-dezembro-2000-377651publicacaooriginal-1-pl.html. Acesso em: 12 jun. 2020.

BRASIL. Lei n. 13.146, de 6 de julho de 2015. Dispõe sobre a Lei Brasileira de Inclusão da Pessoa com Deficiência. Brasília, DF, 7 jul. 2015.Disponível em: http://www.planalto.gov.br/ccivil_03/_ato2015-2018/2015/lei/113146.htm. Acesso em: 25 maio 2020.

BRASIL. Lei n. 13.861, de 18 de julho de 2019. Os censos demográficos realizados a partir de 2019 incluirão as especificidades inerentes ao transtorno do espectro autista, em consonância com o $\S 2^{\circ}$ do art. $1^{\circ}$ da Lei $\mathrm{n}^{\mathrm{o}}$ 12.764, de 27 de dezembro de 2012. Brasília, DF, 19 jul. 2019.Disponível em: http://www.planalto.gov.br/ccivil_03/_ato20192022/2019/lei/L13861.htm. Acesso em: 8 jun. 2020.

BRASIL. Lei n. 13.977, de 8 de janeiro de 2020, Lei, denominada "Lei Romeo Mion", altera a Lei $n^{\circ}$ 12.764, de 27 de dezembro de 2012 (Lei Berenice Piana), e a Lei no 9.265, de 12 de fevereiro de 1996 (Lei da Gratuidade dos Atos de Cidadania), para criar a Carteira de Identificação da Pessoa com Transtorno do Espectro Autista (Ciptea), de expedição gratuita. Brasília, DF, 9 jan. 2020. Disponível em: http://www.planalto.gov.br/ccivil_03/_ato20192022/2020/lei/L13977.htm. Acesso em: 8 jun. 2020.

BRASIL. Lei n. 7.853, de 24 de outubro de 1989. Dispõe sobre o apoio às pessoas portadoras de deficiência, sua integração social, sobre a Coordenadoria Nacional para Integração da Pessoa Portadora de Deficiência - Corde, institui a tutela jurisdicional de interesses coletivos ou difusos dessas pessoas, disciplina a atuação do Ministério Público, define crimes, e dá outras providências. Brasília, DF, 25 out. 1989. Disponível em: http://www.planalto.gov.br/ccivil_03/leis/17853.htm. Acesso em: 15 jun. 2020.

BRAVO, R. S. Técnicas de investigação social: Teoria e ejercicios. 7. ed. Madrid: Paraninfo, 1991.

CAMARGO, S. P. H.; BOSA, C. A. Competência social, inclusão escolar e autismo: um estudo de caso comparativo. Psicologia: Teoria e Pesquisa, Brasília, v. 28, n. 3, p. 315-324, jul./set. 2012. Disponível em:

https://periodicos.unb.br/index.php/revistaptp/article/view/18165. Acesso em: 30 maio 2020.

CANEDA, C. R. G.; CHAVES, T. M. L. A percepção do professor e do tutor frente à inclusão da criança com autismo no ensino regular. Aletheia, Canoas, n. 46, p. 142-158, abr. 2015. Disponível em: http://pepsic.bvsalud.org/scielo.php?script=sci_arttext\&pid=S141303942015000100012\&lng=pt\&nrm=iso. Acesso em: 30 jun. 2020. 
COEPEDE. Conselho Estadual dos Direitos da Pessoa com Deficiência. Folheto sobre Direitos Humanos, Direitos da Pessoa com Deficiência, Incidência da Deficiência, Terminologia. 2011.

CUESTA GOMES, J. L.; GRAU RUBIO, C.; FERNÁNDEZ HAWRYLAK, M. Calidad de vida: evaluación y trastornos del espectro del autismo. Revista Iberoamericana de educación, n. 63, p. 161-179, 2013. Disponível em:

https://rieoei.org/historico/documentos/rie63a11.pdf. Acesso em: 30 jun. 2020.

DECLARAÇÃO DE SALAMANCA. 1994. Disponível em:

http://portal.mec.gov.br/seesp/arquivos/pdf/salamanca.pdf. Acesso em: 10 jun. 2020.

DENZIN, N. K.; LINCOLN, Y. (orgs). Planejamento da pesquisa qualitativa: teorias e abordagens. 2. ed. Porto Alegre: ARTMED, 2006.

DENZIN, N. K.; LINCOLN, Y. A disciplina e a prática da pesquisa qualitativa. 1. ed. Porto Alegre: ARTMED, 2006.

DIGIROLAMO, F. P. Sexualidade da pessoa com deficiência pós ratificação da Convenção da ONU. In: SEMINÁRIO NACIONAL DE SAÚDE: DIREITOS SEXUAIS E REPRODUTIVOS E PESSOAS COM DEFICIÊNCIA, 1., 2010, Brasília. Anais [...]. Brasília: Ministério da Saúde, 2010.

DINIZ, D. Modelo social da deficiência: a crítica feminista. Brasília: Letras Livres, 2003.

GIL, A. C. Como elaborar projetos de pesquisa. 5. ed. São Paulo: Atlas, 2010.

GUEDES, N. P. S.; TADA, I. N. C. A Produção Científica Brasileira sobre Autismo em Psicologia e Educação. Psicologia: Teoria e Pesquisa, Brasília, v. 31, n. 3, p. 303-309, set. 2015. Disponível em http://www.scielo.br/scielo.php?script=sci_arttext\&pid=S0102$37722015000300303 \& \operatorname{lng}=$ en\&nrm=iso. Acesso em: 30 jun. 2020. DOI:

https://doi.org/10.1590/0102-37722015032188303309

IBDD. Instituto Brasileiro dos Direitos da Pessoa com Deficiência. Inclusão social da pessoa com deficiência: medidas que fazem a diferença. Rio de Janeiro: IBDD, 2008.

JEANE A. M. R. A.; VARELLA A. B. Breves Considerações Sobre a Atenção à

Pessoa com Transtorno do Espectro Autista na Rede Pública de Saúde. Revista Psicologia e Saúde, v. 11, n. 1, p. 89-98, jan. 2019. Disponível em:

http:/www.psicc.unb.br/images/livros/psicologia-clinica-e-cultura-contemporanea.pdf.

Acesso em: 30 jun. 2020.

JUNIOR, M. C. M. L. História do Movimento Político das Pessoas com Deficiência no Brasil. Brasil: Secretária de Direitos Humanos, 2010.

MARQUES, D. F.; BOSA, C. A. Protocolo de Avaliação de Crianças com Autismo:

Evidências de Validade de Critério. Psic.: Teor. e Pesq., Brasília, v. 31, n. 1, p. 43-51, Mar. 2015. Disponível em: http://www.scielo.br/scielo.php?script=sci_arttext\&pid=S0102- 
$37722015000100043 \& \operatorname{lng}=$ en\&nrm=iso. Acesso em: 30 jun. 2020. DOI:

http://dx.doi.org/10.1590/0102-37722015011085043051

MINAYO, M.C. S. O desafio do conhecimento: pesquisa qualitativa em saúde. 12. ed. São Paulo: Hucitec-Abrasco, 2010.

MORI, N. N. R. Psicologia e educação inclusiva: ensino, aprendizagem e desenvolvimento de alunos com transtornos. Acta Scientiarum Education, Maringá, v. 38, n. 1, p. 51-59, jan./mar. 2016.

ORTEGA, F. et al. A construção do diagnóstico do autismo em uma rede social virtual brasileira. Interface, Botucatu, v. 17, n. 44, p. 119-132, mar. 2013. Disponível em: http://www.scielo.br/scielo.php?script=sci_arttext\&pid=S141432832013000100010\&lng=en\&nrm=iso. Acesso em: 30 jun. 2020. DOI: http://dx.doi.org/10.1590/S1414-32832013000100010

PESSOTTI, I. Deficiência mental: da superstição à ciência. São paulo: EDUSP, 1984.

RAMIRES, V. R. R. et al. Mudanças na psicoterapia psicodinâmica de crianças na visão de pais e mães. Avances en Psicología Latinoamericana, Universidad del Rosario, v. 37, n. 1, p. 29-46. 2019. Disponível em:

https://revistas.urosario.edu.co/xml/799/79957990004/index.html. Acesso em: 30 jun. 2020.

RIOS, C.; CAMARGO JUNIOR, K. R. Especialismo, especificidade e identidade - como controvérsias no torno do autismo no SUS. Ciênc. saúde coletiva, Rio de Janeiro, v. 24, n. 3, p. 1111-1120, março de 2019. Disponível em:

http://www.scielo.br/scielo.php?script=sci_arttext\&pid=S1413-

$81232019000301111 \& \operatorname{lng}=$ en\&nrm=iso. Acesso em: 30 jun. 2020.

https://doi.org/10.1590/1413-81232018243.07862017

ROSSI, L. P. et al. Caminhos Virtuais e Autismo: acesso aos serviços de saúde na perspectiva da Análise de Redes Sociais. Ciênc. saúde coletiva, Rio de Janeiro, v. 23, n. 10, p. 33193326, out. 2018. Disponível em:

http://www.scielo.br/scielo.php?script=sci arttext\&pid=S1413-

$81232018001003319 \& 1 n g=$ pt\&nrm=iso. Acesso em: 30 jun. 2020. DOI:

http://dx.doi.org/10.1590/1413-812320182310.13982018

SANTOS, R. K.; VIEIRA, A. M. E. C. S. Transtorno do Espectro do Autismo (TEA): do reconhecimento à inclusão no âmbito educacional. Revista Includere, Mossoró, v. 3, n. 1, p. 219-232, 2017. Disponível em:

https://periodicos.ufersa.edu.br/index.php/includere/article/view/7413. Acesso em: 25 jan. 2020.

SCHMIDT, C. Temple Grandin e o autismo: uma análise do filme. Rev. bras. educ. espec., Marília, v. 18, n. 2, abr./jun. 2012. Disponível em:

http://www.scielo.br/scielo.php?script=sci_arttext\&pid=S1413-

$65382012000200002 \& 1 n g=e n \& n r m=$ iso. Acesso em: 16 de jun. 2020

SCHNEIDER, J. A.; LIMBERGER, J.; ANDRETTA, I. Habilidades sociais e drogas: revisão sistemática da produção científica nacional e internacional. Avances en Psicología 
Latinoamericana, v. 34, n. 2, p. 339-350, 2016. Disponível em:

https://revistas.urosario.edu.co/xml/799/79945606009/index.html. Acesso em: 30 de jun. 2020.

SEVERINO, A. J. Metodologia do trabalho científico. 23. ed. rev. e atual. São Paulo: Cortez, 2007.

SILVA DA LUZ, M. H; GOMES, C. A.; LIRA, A. Narrativas sobre a inclusão de uma criança autista: desafios à prática docente. Educación, Lima, v. 26, n. 50, p. 123-142, mar. 2017. Disponível em: http://www.scielo.org.pe/scielo.php?script=sci_arttext\&pid=S101994032017000100007\&lng=es\&nrm=iso. Acesso em: 30 jun. 2020. DOI:

http://dx.doi.org/http://doi.org/1018800/educacion.201701.007

SILVA, A. J. da. Autismo, direito e cidadania. Assembleia Legislativa do Estado do Rio Grande do Sul. Comissão de Cidadania e Direitos Humanos; Rede Gaúcha Pró- Autismo. Alexandre José da Silva. Porto Alegre: Assembleia Legislativa do Rio Grande do Sul, 2017.

SILVA, C. M.; NASCIMENTO, H. T. B. Perturbações do Espectro do Autismo: uma revisão bibliográfica acerca dos benefícios da prática de Educação Física junto aos alunos que têm Necessidades Educativas Especiais. In: ANDRADE, J. M. Teoria e prática da Educação Especial. Manaus: UEA Edições, 2017.

SILVA, L. R. C; DAMACENO, A. D.; MARTINS, M. C. R.; SOBRAL, K. M.; FARIAS, I. M. S. Pesquisa Documental: Alternativa Investivativa na Formação Docente. In: IX CONGRESSO NACIONAL DE EDUCAÇÃO - EDUCERE, 4.; III Encontro Sul Brasileiro de Psicopedagogia, 3., 2009, Curitiba. Anais [..]. Curitiba: PUC-PR, 2009. Disponível em: https://educere.bruc.com.br/arquivo/pdf2009/3124_1712.pdf. Acesso em: 29 jun. 2020.

SIMÕES, J. Sobre deslizamentos semânticos e as contribuições das teorias de gênero para uma nova abordagem do conceito de deficiência intelectual. Saúde e Sociedade, São Paulo, v. 28, v. 3, out. 2019. Disponível em:

https://www.scielosp.org/article/sausoc/2019.v28n3/185-197/\#. Acesso em: 29 jun. 2020.

TELLES, J. L. Direitos Sexuais e Direitos Reprodutivos na Agenda da saúde das Pessoas com Deficiência. In: SEMINÁRIO NACIONAL DE SAÚDE: DIREITOS SEXUAIS E REPRODUTIVOS E PESSOAS COM DEFICIÊNCIA, 1., 2010, Brasília. Anais [...]. Brasília: Ministério da Saúde, 2010.

TIBYRIÇA, R. F. Os direitos das pessoas com (TEA) após a Lei 12.7694/12 (Lei Berenice Piana): o que mudou? São Paulo: Defensoria Pública do Estado de São Paulo, 2015.

VIEIRA, C. S. Educação Física para portadores de necessidades especiais (PNEE). In: ENCONTRO DE ENSINO, 3., 2009, Recife. Anais [...]. Recife, PE: SENAC, 2009. 


\section{Como referenciar este artigo}

SOUZA, A. L. A.; ANACHE, A. A. A educação das pessoas com o transtorno do espectro autista: avanços e desafios. Revista on line de Política e Gestão Educacional, Araraquara, v. 24, n. esp. 2, p. 1035-1053, set. 2020. e-ISSN: 1519-9029.DOI: https://doi.org/10.22633/rpge.v24iesp2.14330

Submetido em: $30 / 04 / 2020$

Revisões requeridas em: 26/06/2020

Aprovado em: 30/07/2020

Publicado em: 30/09/2020 